\title{
A SEMANA DE ARTE MODERNA DE 1922
}

\author{
THE MODERN ART WEEK OF 1922
}

*Elza Ajzenberg

\section{RESUMO}

O presente artigo discute os principais acontecimentos e desdobramentos da Semana de Arte Moderna de fevereiro de I922, realizada em São Paulo, e, sobretudo, coloca o movimento modernista como importante referencial para reflexões estéticas e para a crítica de Arte do país.

Palavras-chave: Arte. Arte Moderna. Semana de Arte Moderna.

\section{ABSTRACT}

This article discusses the main events and developments of the Week of Modern Art in February I922, held in São Paulo, and, above all, puts the modernist movement as an important reference for aesthetic considerations and the Art critic of the country.

Key words: Art. Modern Art. Modern Art Week.

* Professora titular da Universidade de São Paulo e coordenadora do Centro Mario Schenberg de Documentação da Pesquisa em Artes da Escola de Comunicações e Artes da Universidade de São Paulo (ECA-USP) - Av. Professor Lúcio Martins Rodrigues, 443 - Cidade Universitária - São Paulo-SP - 05508-020-e-mail: majzenberg@uol.com.br. 
A Semana de Arte Moderna de fevereiro de I922, realizada em São Paulo, é importante referencial para reflexões estéticas e para a crítica de arte do país. Essa manifestação é potencializada pelo contexto em que ocorre. As questões associadas ao nacionalismo emergente do pós-Primeira Guerra Mundial e à industrialização que se estabelece, especialmente em São Paulo, motivam intelectuais e jovens artistas entusiasmados a reverem e criarem novos projetos culturais.

As comemorações do Centenário da Independência do Brasil incentivam um grupo inquieto diante das possibilidades de traçar um perfil mais livre, com a quebra de cânones que impedem a renovação da criatividade artística. As ideias começam a tomar corpo com os debates em torno da exposição de Anita Malfatti em I9I7-I9I8.

No jornal Correio Paulistano de 29 de janeiro de I922, uma nota anuncia a realização de uma semana de arte no Teatro Municipal, entre II e I8 de fevereiro, com a participação de escritores, músicos, artistas e arquitetos de São Paulo e do Rio de Janeiro. De acordo com a notícia, a Semana, organizada por intelectuais das duas cidades, tendo Graça Aranha à frente, tem por objetivo dar ao público de São Paulo "a perfeita demonstração do que havia em nosso meio em escultura, pintura, arquitetura, música e literatura sob o ponto de vista rigorosamente atual" [9].

No comitê patrocinador estão presentes, entre outros, Paulo Prado, Alfredo Pujol, René Thiollier e José Carlos Macedo Soares. Entre os participantes, figuram músicos como Villa-Lobos, Guiomar Novaes, Ernani Braga e Frutuoso Viana; no grupo de escritores, estão Mário de Andrade, Oswald de Andrade, Ronald de Carvalho, Menotti Del Picchia, Guilherme de Almeida, Ribeiro Couto e Sérgio Milliet. Como diversos participantes da Semana ocupam cargos de destaque nas redações de importantes jornais da época, o evento tem desde o início grande divulgação, embora também não falte quem se oponha à sua concretização [7].

$\mathrm{Na}$ notícia do Correio Paulistano, Graça Aranha é posto como autor da iniciativa. Entretanto, para alguns pesquisadores, é mais provável que essa prioridade se deva a Emiliano Di Cavalcanti, ao acatar uma sugestão de Marinete Prado - esposa de Paulo Prado - que se refere à possibilidade de se fazer em São Paulo algo similar aos festivais culturais de Deauville. Em Viagens de Minha Vida, Di Cavalcanti chama para si a paternidade da Semana, dizendo: "Falamos naquela noite e em outros encontros da Semana de Deauville [...]. Eu sugeri a Paulo Prado a nossa semana [...]" [6]. Manuel Bandeira, referindo-se à organização da Semana, menciona Di Cavalcanti, "pintor de quem partiu a ideia" [5].

Seja quem for o autor da ideia, o objetivo da Semana é renovar o estagnado ambiente artístico e cultural de São Paulo e do país. Acentua-se a necessidade de "descobrir" ou "redescobrir" o Brasil, repensando-o de modo a desvinculá-lo, esteticamente, das amarras que ainda o prendem à Europa. É verdade que os jovens participantes da proposta inovadora procuram a "proteção", a diplomacia e a arregimentação de Graça Aranha - espécie de avalista ou "carro-chefe", capaz de impor respeito a setores menos abertos à modernidade [6]

Chega-se a 1922. A ideia cresce e avança levada por Paulo Prado, figura representativa da intelectualidade e da alta camada social paulista. Os equívocos são muitos. A comissão organizadora, de cunho mais tradicionalista, está distante da sensibilidade realmente moderna de Mário de Andrade, Oswald de Andrade, Di Cavalcanti, Villa-Lobos, Brecheret e Anita Malfatti.

A Semana realizou-se perante aplausos e vaias. Enquanto nos dias I3, I5 e I7 de fevereiro ocorrem, no interior do Teatro Municipal, conferências e concertos, no saguão, os artistas e os arquitetos expõem seus trabalhos. Não são todos os anunciados na nota do Correio Paulistano, pois Regina Graz não participa. Tampouco apenas os citados no catálogo da mostra [2]. Alguns artistas, ausentes do país, só estão representados por suas obras.

O catálogo, idealizado por Di Cavalcanti, registra a participação dos arquitetos Antonio Moya e Georg Prsirembel; dos escultores Victor Brecheret e Wilhelm Haerberg; e dos pintores e desenhistas Anita Malfatti, Di Cavalcanti, John Graz, Martins Ribeiro, Zina Aita, João Fernando (Yan) de Almeida Prado, Ignácio da Costa Ferreira (Ferrignac) e Vicente do Rego Monteiro. O discutível modernismo das obras expostas e a confusão estilística em que se debatem seus autores traduzem-se nos títulos equivocados de algumas pinturas e desenhos, tais como, Impressão Divisionista (Anita Malfatti), Impressões (Zina Aita), Natureza Dadaísta (Ferrignac) ou Cubismo (Vicente do Rego Monteiro). Os "futuristas" de I922, como o público, à época, insiste em denominá-los, praticam de tudo um pouco - Pontilhismo ou Expressionismo, menos Futurismo propriamente dito. O essencial é escapar ao que é conhecido como Academicismo [3]. 
Até hoje, a Semana de I922 é envolvida por questões: o evento provoca choques e rupturas? Acentua um "tom festivo", ou seja, não é um movimento sério? Alcança parâmetros mais críticos em relação à arte? É de natureza mais destrutiva ou constrói novas perspectivas para a estética do país? Os debates persistem.

$\mathrm{Na}$ revisão do próprio Di Cavalcanti, a Semana segue para "um tom festivo, irreconciliável talvez com o sentido de transformação social” que, para o artista, deve estar no fundo de uma revolução artística e literária. Entretanto, Di Cavalcanti elabora depois uma versão mais positiva. Para o artista, a Semana é um acontecimento que abre para o país perspectivas, as quais, extrapolando o campo puramente cultural, têm repercussões inclusive na área política [6].

Alguns críticos consideram imensa a repercussão obtida pela Semana. Outros negam o fato. É o caso de Carlos Drummond de Andrade, em Belo Horizonte, e de Rodrigo Melo Franco de Andrade, no Rio de Janeiro. Os jornais da época assinalam que a Semana tem mais inimigos do que amigos: "inimigos inteligentes". Entre as críticas, diz-se que os envolvidos são "barulhentos" e que o movimento não passa de um "estratagema" [6].

A exposição de arte, propriamente dita, recebe alguns comentários, através das notas de Graça Aranha, Menotti Del Picchia e Mário de Andrade. Porém, considera-se que as ideias disseminadas pelos conferencistas Graça Aranha, Menotti Del Picchia e Mário de Andrade alcançam muito mais eco. Essas questões não impedem, contudo, que obras mostradas no saguão do Teatro Municipal suscitem à maioria do público sentimentos que oscilam do divertimento à indignação. Os grandes alvos são os trabalhos de Anita Malfatti e Victor Brecheret (ver Anexo, Imagens I e 2).

Embora hoje o modernismo exposto pela Semana pareça pouco moderno, que todos os fatos do contexto e artífices nem sempre sejam devidamente citados ou lembrados, e que ainda as ideias estéticas de seus líderes sejam confusas, não se pode negar que a Semana de I922 seja um marco. A Semana representa para a evolução artística brasileira um verdadeiro "divisor de águas".

Ocorrida no ano do Centenário da Independência do Brasil, a Semana difunde a ideia de renovação que, embora já tenha ocorrido anteriormente de maneira isolada, não está consolidada num movimento organizado. Nesse sentido, escreve Paulo Mendes de Almeida que não se trata de um gesto isolado de rebeldia, "mas um clamor em coro, um movimento de grupo $[\ldots]$ um safanão naquele adormecido em berço esplêndido Brasil [...]" [I].

Talvez nunca se encontre um consenso na conceituação da Semana de I922, ou da sua validade ou alcance na evolução no campo estético e nas artes plásticas no Brasil. Entretanto, as constantes revisões assinalam, cada vez mais, a "lição de liberdade no espírito e na pesquisa plástica” presente nos passos seguintes da arte no país. Mário de Andrade enfatiza que o artista brasileiro passa a ter "diante de si uma verdade social, uma liberdade (infelizmente, só estética), uma independência, um direito a suas pesquisas conquistadas pelos modernistas da Semana" [4].

As conquistas da Semana têm desdobramentos que marcam sensivelmente as buscas de um novo modo de pensar. Nesse ponto, Mário Pedrosa é incisivo e acentua aspectos: "a pintura e a escultura alargam extraordinariamente o campo de visão e de interesse dos promotores da Semana." Para Pedrosa, essas contribuições definem a evolução intelectual e artística do país. Nesse sentido, é lembrada a "plasticidade presente nos textos de Mário de Andrade. Através da imagem verbal, em sua projeção, o universal" [4]. Na linguagem atualizada, o primitivo encontra expressão sem fronteiras. Como conquista, o autor de Paulicéia Desvairada e Macunaíma alcança o objetivo duplo do modernismo: a atualização e o nacional [8].

Em síntese, o contexto que envolve a Semana de Arte de 1922 possui denso e rico acervo, envolve questões que merecem novas reflexões. Porém, as várias possibilidades de abordagem não devem perder de vista a assertiva de Mário de Andrade: a Semana logra atingir os seus objetivos primordiais: "[...] o direito permanente à pesquisa estética; a atualização da inteligência artística brasileira; e a estabilização de uma consciência criadora nacional" [4].

\section{REFERÊNCIAS BIBLIOGRÁFICAS}

[I] ALMEIDA, Paulo Mendes de. De Anita ao Museu. São Paulo: Perspectiva, I976. p. 34-35.

[2] AMARAL, Aracy. Artes Plásticas na Semana de 22. São Paulo: Perspectiva, 1970. p. 129 e ss.

[3] ANDRADE, Mário de. A Semana Futurista: Pró. Gazeta, São Paulo, 4 fev. I922. Notas de Arte. 
[4] ANDRADE, Mário de. O Movimento Modernista. In: Aspectos da Literatura Brasileira. São Paulo: Livraria Martins, I967. p. 24I-242. (Obras Completas).

[5] BANDEIRA, Manuel. Apresentação. In: Poesia brasileira. Rio de Janeiro: Livraria Casa do Estudante do Brasil, I954. p. I40-I44.

[6] DI GAVALCANTI, Emiliano. Viagem da minha vida. Rio de Janeiro: Givilização Brasileira, I955·p. 85-II4.

[7] LEITE, José Roberto Teixeira. A Semana de Arte Moderna. In: Arte no Brasil. São Paulo: Abril Cultural, I979. p. 672.

[8] PEDROSA, Mário. Semana de Arte Moderna. In: Dimensões da arte. Rio de Janeiro: MEC, I964. p. I3O-I3I.

[9] THIOLLIER, René. A Semana de Arte Moderna. São Paulo: Cupolo, s/d. p. 5. 


\section{ANEXO}

IMAGEM 1

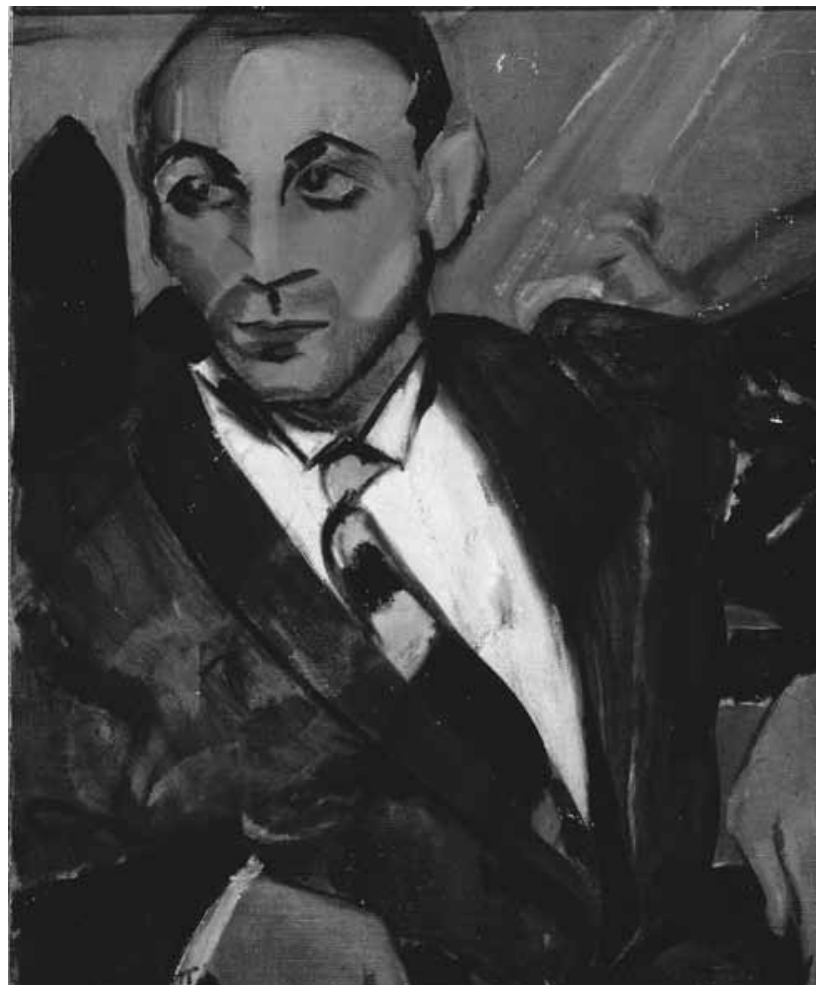

O Homem Amarelo (I9I5/I6), um dos trabalhos expostos por Anita Malfatti na Semana de 22. Coleção Mário de Andrade, do Instituto de Estudos Brasileiros da USP.

\section{IMAGEM 2}

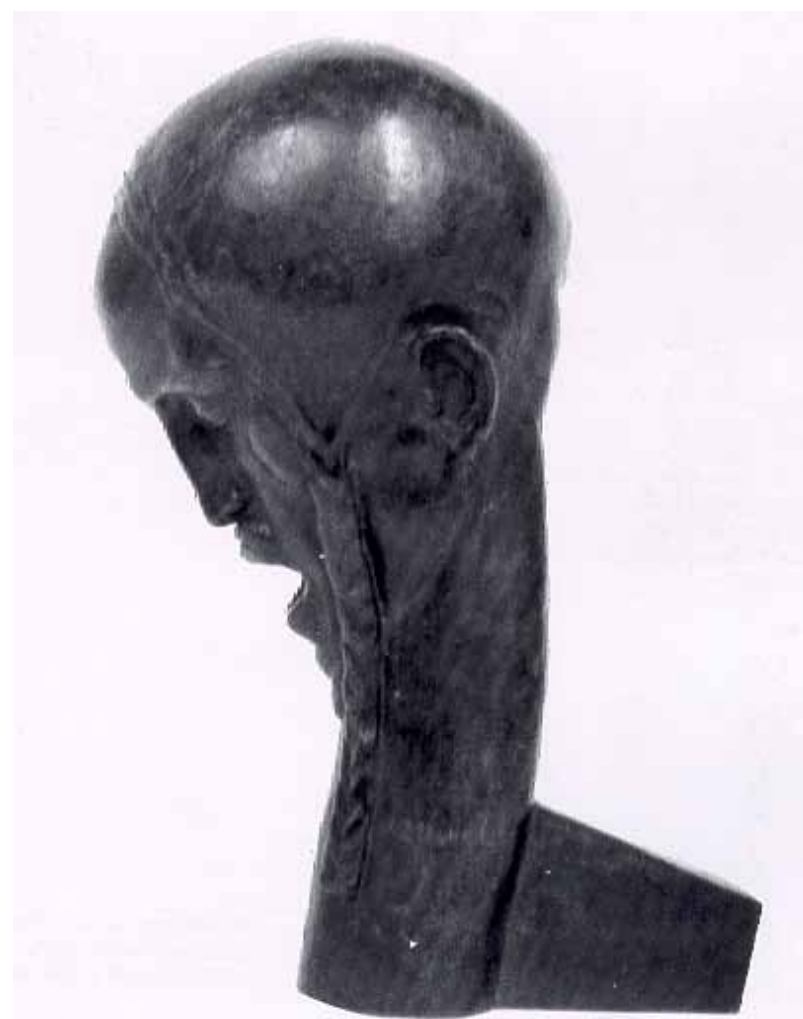

Cabeça de Cristo (I9I9/20 c), obra do escultor Victor Brecheret. Coleção Mário de Andrade, do Instituto de Estudos Brasileiros da USP. 